360-Degree Video Journalism:

\title{
AN ANALYSIS OF THE DIFFERENT ANGLES OF MODERN TECHNOLOGY AND NEWS REPORTING
}

\author{
by \\ Nitish Kelvin Bissonauth \\ (BJourn, Ryerson University, 2015) \\ A Major Research Project (MRP) \\ presented to Ryerson University \\ In partial fulfilment of the \\ requirements for the degree of \\ Master of Digital Media \\ in the \\ Program of Digital Media
}

Toronto, Ontario, Canada, 2017

(c) Nitish Kelvin Bissonauth 2017 


\section{AUTHOR'S DECLARATION FOR ELECTRONIC SUBMISSION OF A MRP}

I hereby declare that I am the sole author of this Major Research Project Paper. This is the authentic, final copy of my MRP, which has been revised and reviewed.

I authorize Ryerson University to lend this MRP to other institutions or individuals for the purpose of scholarly research. Furthermore, I authorize Ryerson University to reproduce this MRP by photocopying or by other means, in total or in part, at the request of other institutions or individuals for the purpose of scholarly research.

I understand that my MRP may be made electronically available to the public.

Nitish Kelvin Bissonauth 
360-DEGREE VIDEO JOURNALISM:

\title{
AN ANALYSIS OF THE DIFFERENT ANGLES OF MODERN \\ TECHNOLOGY AND NEWS REPORTING
}

\author{
Master of Digital Media 2017 \\ Nitish Kelvin Bissonauth \\ Master of Digital Media, Ryerson University
}

\section{ABSTRACT}

This paper will analyse and consider 360-degree videos in the context of previous new technologies and how they changed processes for journalism. Referencing previous research literature, news articles, case studies and my personal experience using 360-degree videos as a videojournalist, this paper will serve as a conceptual review in order to better understand new considerations that might have to be taken when considering 360-degree videos for daily news production. Moreover, this paper will review the introduction of liveblogs and Facebook Live, and how each has fundamentally changed journalism. By doing so, this conceptual review will hope to identify unique challenges and successes that 360-degree video journalism might have for the reporter from a technical, ethical and storytelling point of view. 


\section{ACKNOWLEDGEMENTS}

"Success is a journey, not a destination. The doing is often more important than the outcome" - Athur Ashe

On this particular journey, I would like to express my sincerest gratitude to several people. First, l'd like to thank my professor, supervisor and mentor Gavin Adamson for his belief, guidance and support throughout my classes during my undergraduate degree, and now during this major research project. His input pointed me in the right direction and allowed me to make the necessary changes to focus and hone in on my research. Through Gavin, I was able to seek clarity and a knowledgeable opinion. For that, I am truly grateful. I would also like to thank Paul Moore for being an insightful secondary reader and for never being afraid to challenge and ask questions. Through his approach, I was able to get a different perspective on my research and address issues that were overlooked.

Of course, they were not the only one involved in this journey. I would also like to thank my former producer, Derek Snider and the team at The Weather Network. Derek Snider was instrumental during the initial stages of my research with his suggestions and feedback. I would like to thank him and The Weather Network for given me the opportunity to experiment with 360-degree videos in-house for my research. I would also like to thank Francis D'Souza and Rogers Media for their peaked interest in 360-degree video journalism and for giving me the opportunity to work and continue apply my research as a reporter with CityNews.

Finally, I would like to thank the faculty and my cohort from the MDM program. Throughout the year, their input and feedback has always been welcomed and very much appreciated. Last, I would like to thank my good friend Winona So. Without her support, this journey would have been very lonely and difficult. Thank you for being by my side when I needed you the most. 


\section{DEDICATIONS}

I would like to dedicate my major research project to my mother and father, Preetima and Neil Bissonauth, for encouraging me to pursue my Master's Degree and to specialize in a field that I'm passionate about. I would like to especially thank my mother for always believing in me and for showing tremendous love and support throughout my entire life. I would not be man that I am today without her.

I would also like to also dedicate this research project to my friends, colleagues, and the faculty of the MDM program. Throughout the year, their input and feedback has always been welcomed and very much appreciated.

Finally, I would like to dedicate my research to all those who are aspiring to forge a career in a challenging industry. People may write you off, they might even encourage you to pursue something else. However, it's important to stay true to yourself. Follow your dreams; work hard and everything will fall into place. Keep reinventing yourself and keep the fire alive. This research is dedicated to all the dreamers and believers. 


\title{
TABLE OF CONTENTS
}

\author{
ABSTRACT \\ ACKNOWLEDGEMENT \\ DEDICATION \\ LIST OF CONTENTS \\ AUTHOR'S DECLARATION FOR ELECTRONIC SUBMISSION OF A MRP \\ RESEARCH OBJECTIVES \\ viii \\ RESEARCH METHODOLOGY \\ ix \\ What are 360-Degree Videos? \\ $\mathrm{X}$ \\ Liveblogging: The Online Answer to 24/7 Television News \\ $\mathrm{xi}$ \\ Facebook Live: Redefining Broadcast Journalism \\ xviii \\ The New World of Live Video \\ xxi \\ OUTCOMES \\ xxiii \\ 360-Degree Video Journalism: Flooding in Minto, ON. \\ $\mathrm{xxxi}$ \\ 360-degree Video Journalism: Flooding in Minto, ON. Part. 2 \\ xxxi \\ Conclusion \\ xxxiii \\ REFERENCES \\ xxxiv \\ xxxiv
}




\section{INTRODUCTION}

Journalism serves many purposes and is not defined by technology, nor by journalists or the techniques they deploy. Instead its purpose is defined by the function news plays in the lives of people (Kovach and Rosential, 2014).

Technology and the techniques used for reporting and circulating the news plays a continuing major role in how journalism is presented to the public. This is evident when you consider the introduction of new tools and resources such as liveblogs and Facebook Live. Technology is drastically changing and so are the journalistic norms. Having said that, 360-degree cameras are next in line to bring these changes when it comes to the practice of journalism. 


\section{A Shift in News Consumption}

We are currently witnessing a shift the in the way in which people get their news, as indicated by the research described in this paper. It is important to understand this change in news consumption because liveblogs, Facebook Live, and even 360-degree videos are best supported on smartphones and powered by social media. In a digital age where nearly everyone has a smart phone and access to the Internet, news can be consumed from virtually anywhere. Users can get access to the latest developments as they happen and right at their fingertips.

According to a new survey by the Pew Research Centre, $62 \%$ of Americans adults get their news on social media (2016). Leading the forefront of news consumption is Facebook, with almost two-thirds, $(66 \%)$ who use this social networking site as a source of news. Not too far behind the pecking order is Twitter with nearly six-in-ten Twitter users (59\%) who get news on the site (Gottfried \& Shearer, 2016). In Canada, almost $58 \%$ of users under the age of 35 use Facebook as a source for weekly news, followed by YouTube (24\%), and Twitter (19\%). (Newman, 2016) 
Moreover, the emergence of the Internet as a prominent medium for news consumption has also provided increased opportunity for participatory journalism.

Against that background, I propose three research questions:

1. What kind of impact do these tools and resources have on a mass audience in modern day journalism?

2. What does the adoption of previous tools and resources (liveblogs and Facebook Live) contribute to the discussion.

3. How can previous tools help identify a strategy or a methodology when it comes to using 360-degree video for journalism?

This paper will summarize scholarly articles and will make reference to case studies in order to answer these questions. 


\section{RESEARCH OBJECTIVES}

This research project consists of identifying challenges in order to better

understanding 360-degree video journalism. This research project integrates findings from previous new technologies and techniques such as liveblog and Facebook Live as well as observations from experimenting with 360-degree videos.

This applied research project attempts to achieve the following:

- Research and thoroughly understand effective practice using new technologies for journalism.

- Research, outline, and define some of the best practices for 360-degree video.

- Understand audience motivation, including why this content would be viewed, liked, and shared on social media. 


\section{RESEARCH METHODOLOGY}

The research will be analysed qualitatively through content analysis. Various sources will be used including articles, case studies, research papers, academic journal and personal experience. Conceptual reviews were conducted in understanding how new technology and techniques have conceptually changed journalism over time. This research was then applied to produce four short, 360-degree videos for news. The analysis from these videos were done to highlight and troubleshoot the challenges with 360-degree-videos. In addition to the research, I add my own insight as a videojournalist. 


\section{What are 360-Degree Videos?}

Not to be confused with virtual reality, 360-degree video is as its title suggests; it's a form of video capture that allows the user to look in all the directions of the scene that is being recorded. Instead of simply looking at a flat, two-dimensional image, the audience can now experience spherical filmmaking by moving a device like a smartphone or a tablet around. This method of video capture involves stitching, which combines the edges of the video to create one continuous image. While is can be viewed with goggles or a headset, it is not the same thing as virtual reality. Instead, 360-degree video is the simplest form of immersive video (2015). Virtual reality on the other hand, is a completely immersive experience that is computer generated. The user can interact and move around within their surrounding with a headset. The images are three-dimensional, and although they might look real, what the user sees is a fictional, virtual world.

While both 360-degree video and Virtual Reality have similar properties, it is important to keep in mind that 360 -degree videos capture real spaces in real time. This paper will therefore solely focus on 360-degree videos and the possibilities this new technology can present when it comes to storytelling and immersive journalism. 


\section{Liveblogging: The Online Answer to 24/7 Television News}

Liveblogging was among the first journalism tools to provide live breaking news online so potential challenges for 360-degree videos are anticipated in that medium. In the early years of the Internet, it would have been inconceivable to break news online before print or broadcast (Thorsen, 2011). Today, it is a much different story with news breaking online first and more often on social media. Liveblogs have been variously described as both the death of journalism and an important journalistic development (Wells, 2011). Combining the curation of social media and conventional news reporting, liveblogs allow journalists to go through and prioritise information from secondary sources and present it to the audience in real time (Thurman and Walters, 2012). With liveblogs the latest information is provided at the top, in a reversed-chronological order and that too in increments. This, coupled with the use of multimedia content and sources from a wide variety of platforms such as Facebook and Twitter, makes for a much more layered and complete coverage.

Compared to traditional online news articles, liveblogs offer an edge when it comes to transparency and immediacy; allowing reporters to post developments as they happen including live editing functions, the liveblog audience can also share in this information gathering, sharing and verification, thus making it an 
engaging platform. The Guardian.co.uk, the UK's second most popular newspaper website started experimenting with liveblogs in 1999, starting with soccer and cricket coverage. It wasn't until the London bombings of 2005 that we saw one of the first news stories to be covered by the Guardian.co.uk using the live blog format (Thurman and Walters, 2012).

Since then, the site has seen some great success. Live blogs now have minute-by-minute coverage with the site accounting for 3.6 million unique users (Wells, 2011). Studies from the 2013 Digital News Report from the Reuters Institute for the Study of Journalism also suggest that liveblogs also have a much better retention period as more visitors are staying for longer periods of time than conventional articles or picture galleries on the same subject (2012). The same study also took a look at the popularity of liveblogs in other countries and consumers attitude towards live pages. 


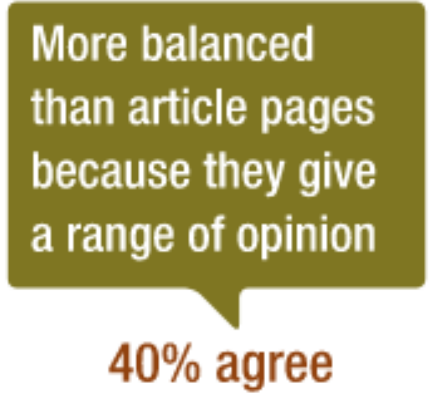

More balanced

than article pages

because they give

a range of opinion

$40 \%$ agree

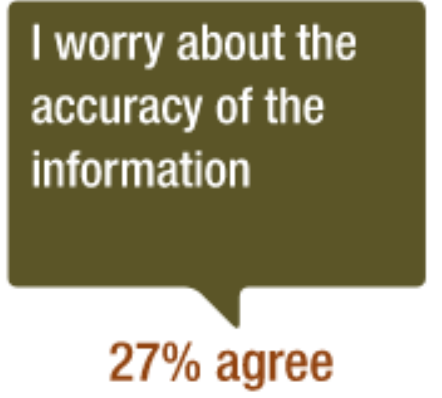

Difficult to under-

stand because the

story is broken up

into short updates

$28 \%$ agree

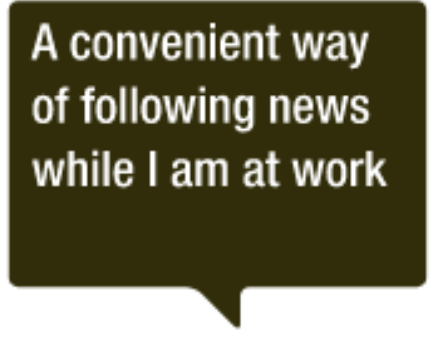

$62 \%$ agree

Figure A, source: Consumer Attitude to Live Pages (Digital News Report, 2016)

As indicated in Figure A, $40 \%$ of consumers find liveblogs more balanced, with only $27 \%$ worried about the accuracy of the content presented.

This speaks to the objectivity in which Live Blogs present. Since it involves attribution as well as verification, not to mention relatively transparent signposting of source material, this may help the audience better judge source credibility (2012). To a certain extent, the same applies with 360-degree videos. Readers can appreciate a neutral tone with the information being corrected quickly and 
the balance that the mix of sources provided (Thorsen, 2011), Liveblogs provide the reader with raw material laid out instead of forcing a narrative. Alternatively, the story tells itself with the information presented.

The raw, unscripted, loose editorial displayed in 360-degree videos was anticipated by liveblogs, which also provided for video uploading. Since 360degree cameras record their surrounding space, the audience can now see everything without having to worry about missing any details. Contrary to traditional, linear news editing, the shots are not organized in a certain way to tell a story. What were once multiple versions of the same story, as a result of different accounts and camera angles is now uniform and standard for everyone when it comes to 360-degree videos (Van Der Haak, Parks \& Castells, 2017). This new form of immersive journalism gives the viewer a first-person experience of the events and the situation described in news stories (de la Peña, 2010). 


\section{Editorial Challenges Presented by New Media}

While liveblogs provide a plethora of information, which in return, allows for better transparency and objectivity when it comes to reporting, the following can also prove to be drawback according to some critics. Robert Mackey, a writer for The New York Times, criticized liveblogs for more or less providing readers with raw material, rather than telling a story (Wells, 2011). Others have condemned liveblogs for having no structure and therefore, no sense. Journalist and blogger, John Symes, describes the platform like "being in the middle of a room full of loud with people yelling all at once, almost like a media circus" (Thorsen, 2011). With the sheer amount of information and the speed in which it is being curated, the reader might find themselves with stories that don't have a defined timescale. This begs the following question; when and how do we know when to end the coverage? (Wells, 2011) One example that comes to mind is the coverage of the Arab Spring. When the uprising began, liveblogs provided situational awareness, where social media gave a better sense of what was happening on the ground (Kiss, 2011).

While the liveblog coverage provided some groundbreaking journalism, the duration of the events unfolding and the sheer amount of information being collected for the coverage presented challenges. Moreover, with liveblogs it is easy to get caught up in the rush of the event. There is no time to make 
connections and analysis since all the information is coming in at once and being funnelled to the top. liveblogs can also be confusing if not properly structured or without a proper end to the reporting.

The same can be said about 360-degree videos. Despite giving access to the full scope of the scene with a 360-degree angled view, this feature can be more distracting than helpful. This is especially true if the story does not require the visuals to be displayed all at once. As with liveblogs, the reporter can find themselves becoming repetitive or redundant because of the images behind them. No matter how much you scroll or move around, you will always end up back to where you started. Not only can this be limiting for the reporter's narrative and storytelling, it can also be distracting for the audience. Liveblogs also face an information overload with important parts of the story buried underneath due to its strict reverse chronology of entries (Belam, 2011).

Similarly, 360-degree videos can also go through an overload, in this case, with the wide scope of images displayed. The reporter might lose the audience's attention if they decided to scroll or move away to a different part of the scene. Consequently, they could miss out on important information presented by the reporter or not pay attention altogether. This ultimately affects the decision making of the reporter's storytelling; the reporter really has to think of their 
narrative in order to make sure the scenes around them are relevant to their story.

Nonetheless, both new technologies offer some advantages for journalism. . When liveblogging, our power of observation are doubled and tripled because we now see things and look for things that we would not otherwise look for in a story (Tenore, 2008). The same goes for 360 -degree videos, where the reporter might look at a situation in a different way because the entire scene is laid out for the audience to see. The reporter might want to incorporate movement and interaction in their reporting by inviting the audience to walk around with him, bringing them to where what they want them to see. This not only captures their attention but also invites them to participate by witnessing the story with them as it unfolds. 


\section{Facebook Live: Redefining Broadcast Journalism}

The exposure to new technology and mobile devices translate to a greater outreach when it comes to viewing and sharing content. This has been the case with Facebook, which has become one of, if not, the most important source of news for the modern day consumers. In 2016, the social networking site introduced its Live feature, which allows anyone to broadcast a video directly from their smartphone, a central component of its growth strategy. (Moon and Volz, 2016) As a result, Facebook's video consumption has increased by $75 \%$ in the past year, reaching 8 billion daily video views (Kalogeropoulos, Cherubini \& Newman, 2016).

With this exposure also comes the opportunity for reporting breaking news much faster than live television. This was especially true during events such as the attacks on Paris and Brussels, where Facebook Live allowed people to see what was going on as it happened (2016). This speaks to the world of immediacy in which we live in; people don't necessarily have the time to wait for the news to air on television.

With the immediacy of Facebook Live video, arrives more challenges; The medium can raise an ethical questions that reporters and users need to answer 
for themselves. . Since the feature has been made available, there have been at least 57 incidents of violence broadcast via live video in the past year (Lewis and Dahmen, 2017). These incidents vary from beatings to rapes, to even murder, broadcasted in real time for the world to see. One of the most notorious incidents is the death of Philando Castile, who was pulled over during a traffic stop and fatality shot by a police officer in Minnesota. His fiancée, who was in the car with him at the time, captured the whole ordeal on Facebook Live. The images were graphic and disturbing, but nonetheless stayed online to garner 4 million views (Moon and Volz, 2016). The video has since been taken down, but Facebook Live still presents a unique challenge; since the broadcast is live, how do you predict of anticipate and incident before it starts?

Traditional television was able to work around this dilemma with short delays or even cutaways to prevent the audience from seeing graphic or disturbing images. In addition, broadcasters are subject to decency standards overseen by the Canadian Radio-Television and Telecommunications Commission and the Canadian Broadcast Standards Council (CBCS). They adhere to the Canadian Association of Broadcaster's Code of Ethics in which Broadcasters shall refer to the $\mathrm{CAB}$ Violence Code provisions relating to the scheduling of programming containing depictions of violence. In that code, it explicitly states that broadcasters shall not telecast programming that sanctions, promotes or 
glamorizes any kind of violence ("Canadian Association of Broadcasters Violence Code," 1993).

Facebook Live, as well as any Internet streaming service, imposes no editorial standards. There are currently no rules or regulations regarding the content streamed online. Although a spokesperson for the social media giant has said in the past that they do not allow people to celebrate or glorify crimes on the social media site, Facebook's standards do not ban torture or violence outright (Byers, 2017).

Consequently, 360-degree video also faces the questions raised about ethics and responsibility on social media. This new form of video capture is supported on Facebook, where it is primarily viewed and it too has live capabilities. The biggest issue for 360-degree video is unintentionally showing harmful images. For instance, if the reporter wants to draw attention to what is going on behind him, the viewer still has the ability to scroll or move somewhere else. Under these circumstances, the reporter not only loses their focus, but also their attention, especially if something is happening on the other side of the camera that has nothing to do with the story. 


\section{The New World of Live Video}

Despite the concerns surrounding Facebook Live and 360-degree videos, both are redefining broadcast journalism. Before a live broadcast was a complicated operation; a crew would be required to set up a satellite box or truck, which was needed, along with access to a cell tower signal. Now it's as easy as opening an application. You are no longer required carry as many personnel or equipment and it take nearly half the time to set up.

It's also noteworthy to mention that Facebook Live and in turn, 360-degree video work well because they have an inherent realism (Lewis and Dahmen, 2017). The audience can associate better with these videos because they have greater authenticity. Since they are both are broadcasted in real time, what you see is what you get. This "liveliness" provides means of collective witnessing, which cannot be experience through any other format of journalism (Peters, 2009). For instance, a reporter acts as a witness at the scene of a crime and reports live on location. The audience is more inclined to believing his live coverage because this format adds to the reporter's credibility; the audience is also bearing witness to what he is seeing. 
Subsequently, this collective witnessing can shed light on certain issues and spark public discussions over social injustices. The Facebook Live shooting of Philando Castile, for instance, showed the compelling and challenging aspects of bearing witness to live event (2017). The video not only exposed the wrongdoings of the police officer but also added to the discussion of police brutality in America.

Finally, Facebook live and 360-degree videos both work well because they are visually stimulating content. More often than not, we are visually oriented. The inclusion of visuals increase our attention as visuals are easier to retain and remember compared to words (2017). In the case of 360-degree videos, the audience can gain a sense of presence. In other words, it is an immersive experience where the viewer can interact with an environment that provides continuous stimuli and has a vivid sense that they are actually there (Fonseca, 2016). And while a sense of presence doesn't alter one's perception of what is going on, it can have an effect on their behaviour. In fact, some studies conclude that consumers with higher sense of presence are more likely to be persuaded after watching infomercials on television than those who felt less presence because the vividness offers the viewer such a realistic experience (2016). 


\section{OUTCOMES}

The ways in which we tell our stories are changing. Along with new technologies come many considerations for news reporting, 360-degree videos can present challenges from a technical, ethical and storytelling perspective for the reporter.

After identifying and analysing similar challenges with Facebook Live and liveblogs, I decided to use my expertise as a videojournalist as well as the arguments from existing literature to see how I would encounter these takeaways while using 360degree videos first hand. I decided to experiment with 360-degree cameras and produce four short pieces of 360-degree video journalism in order to better understand and learn how to properly use this tool in order to create a new, immersive style of storytelling, and in the process, provide a more enriching experience for the audience.

After experimenting on four different occasions, I can confirm that 360-degree video does present similar challenges to Facebook Live and liveblog from a technical, ethical and storytelling perspective. Here is how these factors come into play. 


\section{Technical Difficulties Introduced by 360-Degree Cameras}

Unlike traditional broadcast cameras, 360-degree cameras are small and compact. They are much easier to carry around. Writing as a videojournalist who often travels and works alone, this feature is very practical. The size, however, is also one of its downfalls. Because of the shape and because it's so small, 360-degree cameras do not have any settings you can adjust on the camera itself. It also doesn't have any playback or external audio hook-up capabilities. There are some of the 360-degree cameras that allow you to view the image by connecting to and using your smartphone as a monitor. However, the make and model I was using didn't have any of those features. That being said, I would often shoot without being able to check the image or audio quality beforehand. This had a major impact on my story about urban agriculture, a story I shot on Ryerson University's rooftop garden. Here are some of the technical challenges I encountered while shooting for that story. 


\section{Lighting challenges}

With 360-degree cameras, you can't adjust the aperture. You cannot control the amount of lighting you let into the camera. In light of this, it is imperative to be mindful of the positioning of the sun. Since I was recording on an open rooftop, this was a challenge. Unfortunately, I stood with the sun behind my back.

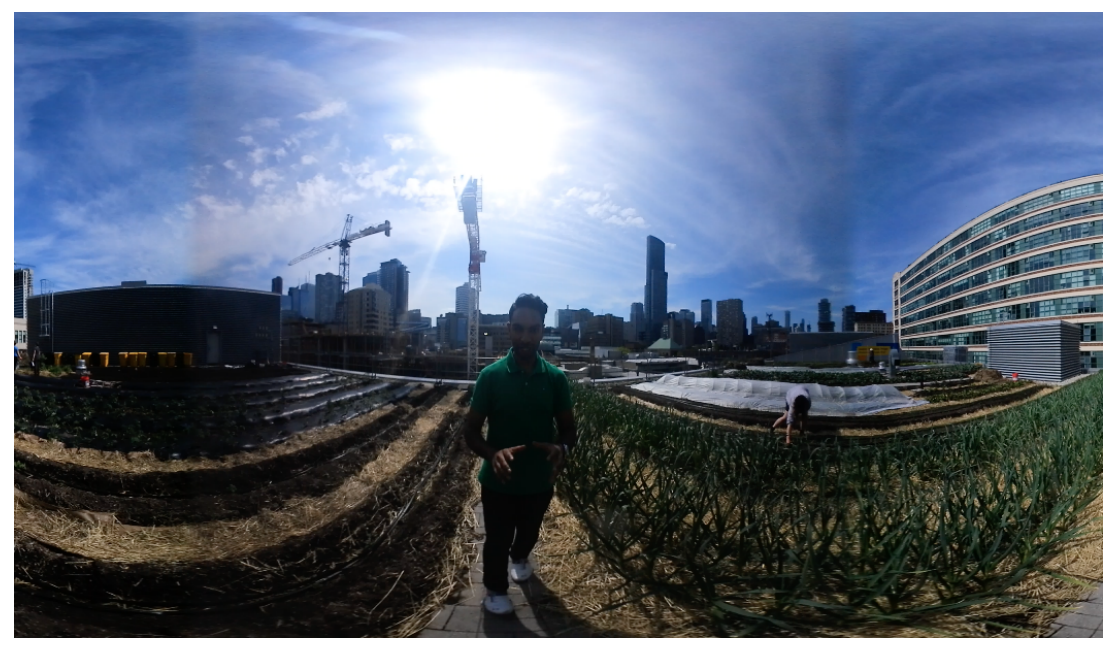

As a result, the video was underexposed and I appeared as a shadow. I had no way of catching this beforehand, nor could I go back and review the shot and make the

proper adjustments. I only noticed the lighting issue when I reviewed the footage in postproduction. What I should have done is reposition my interview guest and myself. Ideally, I would want to record when the sun is not as strong and bright. One recommendation I would have for the technology is for manufacturers to develop a detachable filter for different colour temperatures. I noticed that the camera I was using had a protective case. Perhaps they could find a way to develop a filter that would be easy to put on, without ruining the image capture or quality. 


\section{Audio Capture}

As mentioned before, 360-degree cameras do not have an external audio connection for a microphone. The reporter therefore has to be mindful of the distance between them and the device. This is something that didn't occur to me. During my shoot on the rooftop, I made the mistake of placing my interview guest and myself a little further away from the camera. I was still quite surprised and impressed by the audio pickup and only the audio wasn't clear when I had my back turned away from the

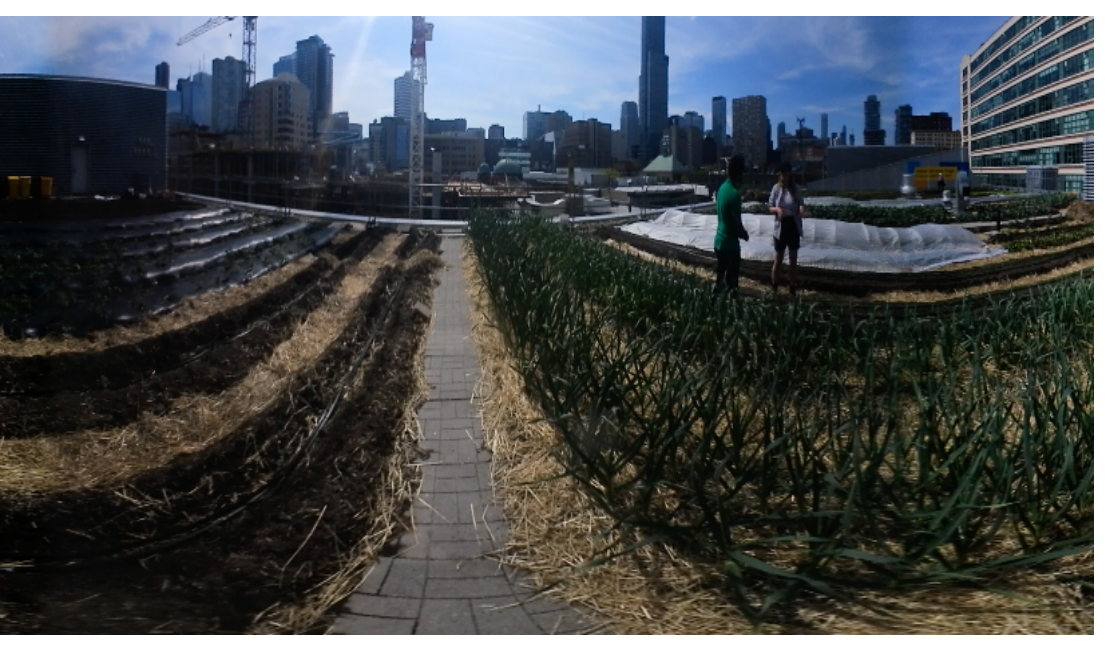

camera. One way to troubleshoot this is to have a secondary audio source recording simultaneously with the 360-degree camera. You could then synchronize the audio with the footage in postproduction. Of course, this requires a bit more time and work to set up. Not to mention the challenge of properly matching the audio with the image afterwards. 


\section{Mind the Stitch}

With 360-degree footage, you're not just looking a flat, two-dimensional image. Instead, the audience experiences spherical filmmaking. An experience that allows you to view the image by swiping through or moving devices like smartphones or tablets around. This method of video capture involves stitching which essentially combines the edges of the video to create one continuous image. That being said, it is important to know where the stitching on the camera is located, essentially on in the extremities of the camera.

Unfortunately I wasn't aware of this and as a result my interview guest and I ended up directly on the stitch for a good portion of the video. In order to avoid being cut in half or look distorted, it's important to set up a marker and be mindful of where you

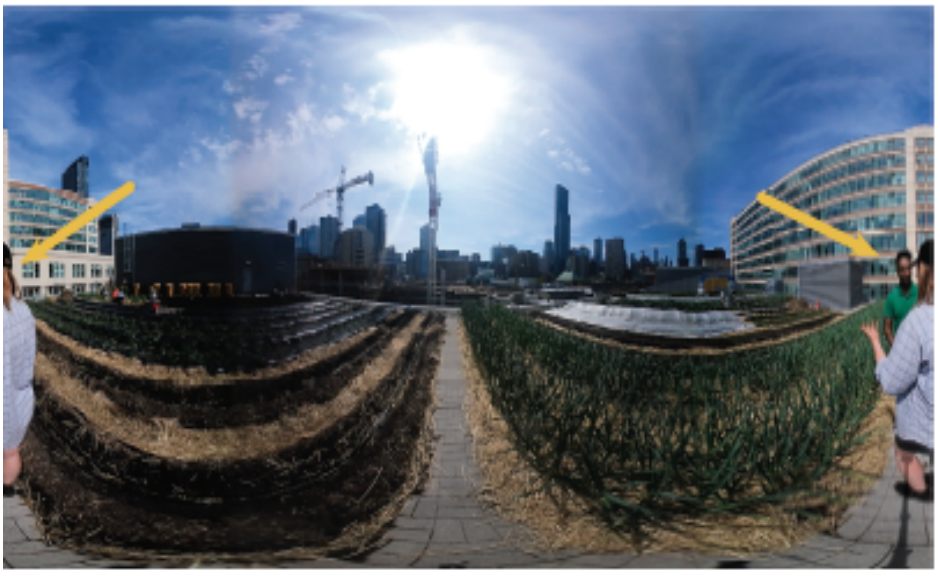

$\Rightarrow$ The reporter has to be mindful of where the stitching on the camera occurs in order to avoid looking distorted or cut in half. stand. This speaks to space

awareness; I found that

navigating through the garden

was harder that I initially

anticipated and that the

movement didn't come off as

organic or natural. Not to

mention the whole concept of 360-degree video capture was 
new to my interview guest. Having to explain to her how it works and then try it for the first time definitely had an impact on the interview and storytelling.

While the issues presented above are simply technical and don't necessarily change the journalism, they are integral when it comes to presentation and audience retention. As a videojournalist, I can say that the production quality of content is very important for news organisations. The slightest issue with audio or visual can be distracting and in some cases off-putting for the audience. It's for that reason that videojournalist are always asked to not only be meticulous with their reporting, but also with their shooting as it is just as important.

You can see how these technical difficulties first hand here: https://www.youtube.com/watch?v=AECHrDKv2Lg 


\section{Ethical Dilemmas Posed with 360-Degree Videos}

Although I didn't face any major ethical dilemmas, as anticipated based on the case study done with Facebook Live, one issue that did arise was the nonconsensual capture of someone on camera. My video about stories inside a tipi is a prime example. Since I was recording in between storytelling sessions, people were allowed wait inside the tipi, where I had set up. A gentleman approached me after my interview in regards to the camera I was using. After explaining what a 360 -degree camera is, he asked if there was a possibility to edit people out of the shot. I then realized that because of the parameters and the restrictions in post-production, one can easily find themselves in a situation where they record someone without their permission. This is an ethical concern because it can violate one's right to privacy, especially if the person isn't part of the story or in this case, involuntarily in the background. Again, because 360- 
degree cameras capture the entire space, we run into the issue of capturing images that are not wanted or needed.

You can see my ethical dilemma posed with 360-degree video here: https://www.youtube.com/watch?v=3McK-G-SM-c

\section{How 360-degree videos affects the narrative and thought process of the reporter}

One of the few videos that did work from a technical and ethical point of view was my coverage of the flooding in the town of Minto, Ontario. This event had all the ingredients for a successful experiment. For starters, it was visually appealing; with a flood zone there's a lot to see and show. As a result, this event helped me realize how 360-degree video can affect the narrative of the reporter, not to mention the interaction with the viewer and the environment. When I started recording, I immediately noticed that I had to change my talking points. In order to keep my viewers attention, I now had to acknowledge or incorporate every moving action around me. If I didn't, there would be a good chance that action would become a distraction and I would then lose the viewer's attention. The best example is the truck that drove past me in the video. Not only did I have to talk about how it's struggling to navigate through the high water levels, I now had to walk in the direction it was heading in since the viewer would most likely be inclined to follow it. 
On the other hand, this experiment also helped me realize that with 360-degree video, while my voice may not be the focal point at all times, I could become a curator of this experience by inviting the viewer to draw their attention to certain things in certain directions. With the 360-degree camera, I was able to invite the audience to follow me as I directed them to different visuals such as the submerged sidewalk and the local business in the water, thus changing the conventional narration of a reporter. Furthermore, I was able to give the audience a better idea of the extent of the damage and a feel for what it's like being on the ground by looking down and seeing the depth of the water. Since the viewer is not limited to a linear viewpoint or a horizontal plane, this gives a better first person perspective of the scene, making this a truly immersive experience. The only downside was that because there was so much action going on, I found it hard to properly organize my narrative from start to finish and properly wrap up, a similar problem I anticipated when analysing liveblogs.

You can experience the flooding in Minto, Ontario and see my coverage with the links below:

360-Degree Video Journalism: Flooding in Minto, ON.

https://www.youtube.com/watch?v=fYHQV5Q4Irw

360-degree Video Journalism: Flooding in Minto, ON. Part. 2

https://www.youtube.com/watch?v=ExqALWBtqEo 



\section{Conclusion}

There's no denying that journalism and storytelling still play a vital role in our society and I believe it will continue to do so for years to come. However, the ways in which we tell our stories are changing. With more people consuming their news in the form of videos on their smartphones and mobile devices, it comes with no surprise that new technologies are bringing different considerations when it comes to news reporting. The likes of liveblogs and Facebook Live, for instance, have conceptually changed journalism from a technical, ethical and the storytelling point of view. So much so that the same takeaways can give us a better insight as to how 360 -degree videos might be considered for daily news production. It is imperative that journalists and news organizations understand and learn how to properly use this tool in order to continue create a new, immersive style of storytelling. 


\section{REFERENCES}

Byers, D. (n.d.). 'Facebook Live' torture video raises ethical questions for social media giant. Retrieved from

http://money.cnn.com/2017/01/05/media/facebook-torture/index.html

Canadian Association of Broadcasters Violence Code (1993). (n.d.). Retrieved June 11, 2017, from http://www.cbsc.ca/codes/cab-violence-code/

Charlie Beckett 22 February 2011 (n.d.). Is Guardian live blogging really the "death of journalism"? Retrieved June 11, 2017, from http://www.currybet.net/cbet_blog/2011/02/guardian-live-blogging-death-ofjournalism.php

Fonseca, D. (n.d.). Retrieved April 20, 2017, from http://projekter.aau.dk/projekter/da/studentthesis/effect-of-immersive-360-videoon-attitude-and-behavior-change(9c5a4dde-0639-4ffc-9d40-63217ccb423a).html

Gottfried, J., \& Shearer, E. (2016, May 26). News Use Across Social Media Platforms 2016. Retrieved June 10, 2017, from http://www.journalism.org/2016/05/26/news-use-across-social-media-platforms$\underline{2016 /}$

Kalogeropoulos, A., Cherubini, F., \& Newman, N. (n.d.). The Future of Online News Video - Reuters Institute ... Retrieved October 20, 2016, from http://digitalnewsreport.org/publications/2016/future-online-news-video/ 
Kiss, Jemima (2011) 'Andy Carvin: the man who tweets revolutions', The Guardian [online], 4 September 2011, Available at: <http://www.guardian.co.uk/media/2011/sep/04/andy-carvin-tweets-revolutions>

Kovach, B., \& Rosenstiel, T. (2014). The elements of journalism: what newspeople should know and the public should expect. New York: Three Rivers Press.

Lewis, S., \& Dahmen, N. S. (2017). What Facebook Live means for journalism. Retrieved from http://theconversation.com/what-facebook-live-meansfor-journalism-72233

Moon, A., \& Volz, D. (2016, July 08). Facebook Live streaming of shooting spotlights ethical, legal policies. Retrieved June 11, 2017, from http://www.reuters.com/article/us-minnesota-police-facebook-idUSKCNOZN2MN

Newman, N. \& Fletcher, R. (2016). Reuters Institute Digital News Report 2016 Retrieved February 21, 2017, from https://reutersinstitute.politics.ox.ac.uk/sites/default/files/Digital-News-Report2016.pdf

Nielsen, R. K., \& Sambrook, R. (2016). What is happening to television news? Retrieved October 15, 2016, from http://reutersinstitute.politics.ox.ac.uk/publication/what-happening-television$\underline{\text { news }}$

Peña, N. D., Weil, P., Llobera, J., Spanlang, B., Friedman, D., SanchezVives, M. V., \& Slater, M. (2010). Immersive Journalism: Immersive Virtual 
Reality for the First-Person Experience of News. Presence: Teleoperators and Virtual Environments, 19(4), 291-301. doi:10.1162/pres_a_00005

Peters, J. D. (2009). Witnessing. Media Witnessing, 23-48. doi:10.1057/9780230235762_2

Prat, C. (2015, October 23). What is 360-degree video, and how can we apply this to journalism? Retrieved June 10, 2017, from https://medium.com/@webDOCC/what-is-360-degree-video-and-how-can-weapply-this-to-journalism-1def4a5fefc3

Reuters Institute for the study of Journalism. (n.d.). Retrieved April 8, 2017, from https://reutersinstitute.politics.ox.ac.uk/

Tenore, M. J. (2008, March 28). Live Blogging: How It Makes Us Better Journalists. Poynter. Retrieved from https://www.poynter.org/2008/live-blogginghow-it-makes-us-better-journalists/87930/

Thorsen, E. (n.d.). Live Blogging and Social Media Curation: Challenges and Opportunities for Journalism. Retrieved June 10, 2017, from http://www.academia.edu/4719570/Live_Blogging_and_Social_Media_Curation_ Challenges_and_Opportunities_for_Journalism

Thurman, N., \& Walters, A. (2013, November 01). Live Blogging- Digital Journalism's Pivotal Platform? A case study of the production, consumption, and form of Live Blogs at Guardian.co.uk. Retrieved June 10, 2017, from http://openaccess.city.ac.uk/1742/ 
Thurman, N., (2013, May 01) How Live Blogs are Reconfiguring Breaking News. Retrieved June 11, 2017, from

http://www.digitalnewsreport.org/essays/2013/how-live-blogs-are-reconfiguringbreaking-news/

Wells, M. (2011, March 28). How live blogging has transformed journalism. Retrieved June 10, 2017, from https://www.theguardian.com/media/2011/mar/28/live-blogging-transformsjournalism 
